\title{
Social Practice of Chinese College Students :The Present Situation, Problems, and Solutions
}

\author{
Ying Yuan ${ }^{1,}$, , Yunfeng Yang ${ }^{1, b}$ \\ ${ }^{1}$ Harbin Institute of Technology, Harbin, P.R. China, 150001 \\ ayuanying@hit.edu.cn, byangyunfeng_hit@126.com
}

Keywords: Social Practice; College Students

\begin{abstract}
The solutions to present situation for the Chinese college students in facing to the requirement of society, magnet for the society and major characteristics in current society is described in this article. And a series of going-on problems, like plain incentive measures, lack of training content standardization, unscientific evaluation system, during the development of social practice activities were analyzed. This article provides several proposals like competent social practice resource, establishing complete social practice system, building up long-lasting social practice mechanism, and provides a series of consultant for colleges to develop social practice activities.
\end{abstract}

\section{Introduction}

College students are able to understand society, touch the truth, transfer the idea, receive education, handle to practice, improve the talent during society practice, and meanwhile, they bring new ideas to the society. They provide their ideas and proposals to the local government, provide technical help to high and new corporations, provide their effort and time to new countryside, and they did a lot of contributions to the progress of local economy, technique, social culture.

\section{The present situation of social practice of Chinese college students}

In China, there are series of college social practice activities, which have rich content. From the aspect of main target, it mainly consists of the following three aspects:

College student social practice caters to social requirement. As the development of China central-west district, socialism new countryside development and the development of some other giant systematic projects facing to multi-domain, a lot of intellectual resources input of multi-major, multi-knowledge, multi-channel, multi-formation are in emergency need and it provides a great stage to college students. The organizer of the college student social practice normally focuses their attention on the practical requirement of society. They lead the students to develop social practice to the places China needs, to understand the current condition of society, and realize their own value. The Central Committee, the provincial Party committee, the College Youth League have developed a series of college social practice activities from different aspects as well. For instance, college students volunteer go to serve in the western region to the western region as volunteers for a year or to the local volunteer local construction. They promote the local economics, technology, culture development; they carry out activities, like take care of the children of migrant workers, pay close attention to left-behind children and other social practice, to help vulnerable groups, in order to solve social problems and provide advice and suggestions. They develop new socialism countryside investigation; understand the present situation of rural. They visit the local field to study and put forward some reasonable suggestions to the local government and farmers. They cooperate with the community, police departments, make an employment social practice, and let students utilize their own advantages to serve the society and at the same time cultivate their own occupation maturity, a good foundation for the employment of college students.

College student social practice faces to the social magnet. As the appearance of social problems, it is crucial to lead college student focus on the people life and develop the social responsibility and 
host conscious by combine the social practice and society magnet issues. Lead the college students to develop the social practice investigation on taking up an occupation. Let them see the situation of finding jobs and the development in the industry and help them find their own position to have a rigid foundation for their long-way development. Lead the college students develop the social practice on medical security, and investigate the conflict among society medical resources. Lead the students think deep and get the ability of resolve social problems. Lead the students develop the social practice investigation on ecological environment, and basic requirements thoroughly Scientific Outlook on Development all-round development, coordinated development and sustainable development. Guide students to carry out economic development, social practice research. Provide a broad platform for college students to in-depth study of housing problems, business problems; Guide students to carry out cultural development in terms of social practice research, and put forward constructive suggestions for the construction of the socialist core value system of real and virtual network culture propagation problems.

College student social practice faces to major characteristics. With the specialized study, especially need to guide the master's and doctoral high-end talent development closely combined with the social practice and professional characteristics. Utilize the application of theoretical knowledge to think and solve problems in practice. On the one hand, college students solve practical problems through the use of their professional knowledge in social practice activities, and students' great interest in learning is cultivated. On the other, let students know that the social needs of their own professional, occupation planning for students in the future also played a very good role in guiding. Science-engineering students set up practical science and technology team, technical work in all industrial sectors and enterprises and new technology promotion work improvement, just like office automation, computer training. Management students to set up scientific management team, in-depth rural township enterprises and management, research, planning and promote the development of agricultural township enterprises driven. While humanities students founded the social investigation unit, field trips, the development of local tourism resources to attract foreign capital inflows, help to invigorate the local economy. Agriculture and forestry students set up scientific breeding unit, investigated and analyzed some problems in the crop, livestock and other aspects of the farmers, and give reasonable suggestions. Law students set up legal consulting team, to provide legal aid to the legal problems of units or individuals, through publicity etc. Medical students set up medical teams, compulsory for people who need help to provide medical help.

\section{The main problems and analysis of social practice of Chinese college students}

In the period of hot development of Chinese college students social practice, it is not hard for us to see the following three problems from the several steps of organizing college students social practice activities.

The incentive measures are not deep enough before the practice. With the change of contemporary college students' ideological and gradually diversified, college students in social practice views are different. Some college students are not aware of the social practice is important for the whole education system, including the important function it affect to themselves and the refuse to be a member in society practice activities. The organizers for outstanding individual achievement and social practice do not carry out extensive publicity, and it results in that there is no more participates in the social practice of the students are not able to share the huge gains in social practice. The honor and reward for funding are limited, which can not constitute the main factors to guide college students to participate in social practice.

The training content is not standard enough in practice. In the social practice in the organization process, we usually pay attention to the social practice subject arrangement, but ignore to face many problems in the process of the social practice of college students. For example, for the selection of practice subject, application of practice methods, the selection of practice place, the selection of practice team organization, the development of practice, the summary of practice are not 
organized very well. In the process of practice to carry out practical activities, there is no standard procedure which can be consulted, and some steps of social practice link are missing or incomplete.

The scientific evaluation system is not enough after the practice. After the social practice, it is difficult to use a perfect evaluation system of social practice to give a summary, usually because of the diversity of social practice, as well as the theme, the number of persons, regions, funding, and methods. Most universities in the evaluation practice of project results are mostly focused on the results application forms and the summary of social practice papers. Some colleges only focus on the beginning, but not pay attention to further summary. Some have very simple summary and pay much attention on the results but not the consulting of problems. Some selected coarsening, only pay attention to choose a few outstanding typical, ignore the evaluation for most participants. Some only pay attention to the advanced individual award, ignore the promotion of experience. These practices have a bad effect on the showing of social practice function and effect, making some students be affected on their active participating in social practice.

\section{The advice for the problems aiming at social practice of Chinese college students}

Equip adequate social practice resources. Increase the practice of carrying out the support of the human resource, material and financial resources for a further step. Mobilize and encourage social work practice. Social practice is a good supplement to the first course. Transfer part of the classroom teaching into social practice, such as the ideological and political education is conducive to carry out ideological and moral education of students. Designate a responsible person for social work practice; ensure the inheritance of social work practice, which is beneficial to the development of social work practice better. Equip a unified social practice of publicity, publicity materials, equipment practice tools, which guarantees social practice work in an orderly manner. Provide greater financial support, the establishment of special funds to ensure the social practice, to carry out various forms of social practice which has deep contents.

Construct perfect social practice system. With the development of social practice, the social practice system is to be gradually improved, and each link of social practice should also be standardized. The social practice should be put into the school's overall education program. For instance, in the graduate student stage, it is necessary to set up postgraduate social practice credits. And students must participate in a certain period of time each year for the ability and skill requirements of social practice. We may consider putting the summer social practice content directly into the teaching plan and co-ordinate arrangements. Expand the social practice field and scale, and combine the college summer social practice and quality education to realize the organic combination of theory teaching and practice teaching. Establish the social practice leading group, and unify leadership of school social work practice, by the Communist Youth League, educational departments arrange the content of social practice, funds, practice spots, teachers, teaching requirements and standards.

Establish long effect social practice mechanism. To make the social practice stepping into society, the only method to accomplish the social practice work is to contact with powerful resources in all aspects of society, to find social power support for the social practice by funding. Colleges and universities should establish school, department of social practice of the organization and employ company responsible person as a consultant, and establish a long-term cooperative relationship with all levels of government and enterprises and institutions. Establish the social practice base and the effect of social practice should be tested by the society. Promote the employment of university students through social practice, but not only by meeting the employer demand for talent, also by meeting the school personnel training and their own development needs. In this way, the college can use the limited funds with the practice unit support to complete the social practice education task, and test whether the talents can realize the need of the society, so as to realize the win-win situation. 


\section{References}

[1] Zhang.Wen and li.Chengtao: Construction the Quality Standard and Evaluation Mechanism of College Student's Social Practice. Physics Procedia. Vol.25(2012), No. 01, p.2287-2290.

[2] Boehm.A and Cohen.A: Commitment to Community Practice Among Social Work Students: Contributing Factors. Vol.49(2013), No. 4, p.601-618.

[3] Anonymous: Should Government Dictate Students' Social Practice Activities. Beijing Review. Vol.53(2010), No. 48, p.46.

[4] Randall. H and Csikai.E: Social work students - A rural innovative practice solution?. Psycho-oncology .Vol.15(2006), No.2, p.376-377.

[5] Bundy.K, Quijano. L and Buba.R: Graduate students' perceptions of professional power in social work. Journal of Social Work Education. Vol.49(2013), No.1, p.108-121. 